\title{
Política de formação de educadores do campo no contexto da expansão da educação superior
}

\author{
Mônica Castagna Molina \\ Universidade de Brasília \\ Salomão Mufarrej Hage \\ Universidade Federal do Pará
}

\section{Resumo}

artigo analisa a política de formação de professores no contexto da expansão da educação superior do campo, focando as tensões entre a matriz demandada pelos movimentos sociais camponeses e a política hegemônica assentada nas orientações dos organismos internacionais, para ajustar a formação profissional às mudanças atuais no sistema produtivo. Ele resulta de pesquisa bibliográfica e documental que analisou legislações e programas relacionados à políitica oficial de formação de professores e o Procampo - Programa de Apoio às Licenciaturas em Educação do Campo, concebido enquanto políitica que contribui para uma formação crítica de educadores formuladores e disseminadores da contra hegemonia.

Palavras-chave: Ensino superior. Formação de professores. Educação do campo.

\section{Formation policy of countryside teachers in the context of expansion of higher education}

\section{Abstract}

The article analyzes the teacher training policy in the context of the expansion of higher education in the countryside, focusing the tensions between the demanded matrix by peasants' social movements and the hegemonic policy defined as a requirement of international organizations to adjust the training to current changes in the production system. The text results from bibliographic and documentary research that analyzed legislation and programs that address the official policy of teacher training and the Procampo, Support Program Degrees in Rural Education, understood as a policy that contributes to a critical training of formulator and disseminator teachers of the counter-hegemony.

Keywords: Higher education. Teachers' formation. Rural education. 


\section{Política de formación docente en el campo en el contexto de expan- sión de la educación superior}

\section{Resumen}

EEl artículo analiza la política de formación docente en el contexto de la expansión de la educación superior en el campo, centrándose en las tensiones entre la matriz demandada por los movimientos sociales campesinos y la política hegemónica sentada en las directrices de las organizaciones internacionales, para ajustar la formación a los cambios actuales en sistema de producción. El artículo el resultado de la investigación bibliográfica y documental que examina las leyes y programas relacionados con la política oficial de la formación del profesorado y los Procampo, Grados Programa de Apoyo a la Educación Rural, entendida como una política que contribuya a formación crítica de educadores fabricantes y divulgadores de contra-hegemonía.

Palabras-clave: Educación superior. Formación del profesorado. Educación del campo.

\section{Introdução}

Este artigo, financiado pela Coordenação de Aperfeiçoamento de Pessoal de Nível Superior (Capes), integra a pesquisa "Políticas da Expansão da Educação Superior no Brasil", realizada a partir do Observatório da Educação Superior, desenvolvida por sete subprojetos e executada por pesquisadores de diversas Instituições de Ensino Superior (IES) no País.

$\bigcirc$ objetivo geral da referida pesquisa é analisar as políticas da expansão da Educação Superior no Brasil, a partir de 1995, considerando as mudanças econômicas, políticas e sociais em curso e as reformas institucionais advindas da Reforma do Estado brasileiro. Um dos sete subprojetos tem como foco a análise da expansão da Educação Superior do Campo e de suas contribuições para o desenvolvimento rural e para a sociedade brasileira.

Uma das frentes da expansão da Educação Superior do Campo tem se dado no âmbito da formação de educadores, com a implementação de 42 cursos em Instituições de Educação Superior brasileiras de uma nova modalidade de graduação, concebida a partir da demanda dos movimentos sociais, intitulada "Licenciatura em Educação do Campo." 
Em função dos pressupostos teóricos que orientam o Movimento da Educação do Campo, é questionável se haveria alguma possibilidade de essa política de formação de educadores, conquistada pelos movimentos sociais camponeses e seus aliados, significar um espaço de acúmulo de forças e de desenvolvimento de experiências, que possam recuperar e ampliar os espaços de práticas de formação de educadores como sujeitos históricos sociais, capazes de formar novas gerações de jovens e adultos a partir de uma perspectiva humanista e crítica. Os cursos de Licenciatura em Educação do Campo (LEDOC), dada sua vinculação material de origem, poderiam enfrentar a hegemonia das atuais políticas de formação no Brasil, orientadas predominantemente pela chamada "Epistemologia da Prática"?

Na primeira parte deste artigo, buscando refletir acerca das questões explicitadas, a partir das leituras que se tem feito no âmbito da pesquisa citada, apresentamos uma síntese das principais políticas que têm materializado essa concepção hegemônica, cujos principais fundamentos relacionam-se à concepção da relação teoria e prática na formação dos educadores. Na segunda parte, buscando explicitar a diferença dessa mesma relação - a começar da compreensão do Movimento da Educação do Campo, o qual teve forte incidência na elaboração da matriz formativa das Licenciaturas em Educação do Campo -, apresentamos a compreensão da relação teoria e prática que consideramos constituir a matriz que orientou a elaboração da política de formação de educadores do campo, materializada no Programa de Apoio às Licenciaturas em Educação do Campo (Procampo).

A partir dessa compreensão, indagamos: pode-se considerar o território conquistado para ampliação desses 42 novos cursos como espaço de acúmulo de forças para elevação da consciência das classes trabalhadoras do campo?

Considerando a tese defendida por Neves (2013) e fundamentada no pensamento gramsciano, que considera os professores intelectuais estratégicos na disseminação da nova pedagogia da hegemonia, este artigo pretende reunir e organizar argumentos para subsidiar a hipótese segundo a qual, apesar dos riscos da expansão, dados os princípios originários do Movimento da Educação do Campo e de sua intrínseca vinculação com a luta de classes, há elementos presentes na concepção dessa política que podem contribuir para promover uma formação crítica e transformadora, que, ao invés de formar educadores do campo como intelectuais da disseminação da nova pedagogia 
Política de formação de educadores do campo no contexto da expansão da educação superior

da hegemonia, forme educadores formuladores e disseminadores da contra-hegemonia, capazes de compreender e promover a necessária articulação das lutas entre as escolas do campo e as lutas para superação dos pilares que sustentam a estrutura da sociedade capitalista.

Para fundamentar essa reflexão, tomamos, como referência, os trabalhos de Helena Freitas (1999, 2002, 2003, 2007); Silva (2012); Freitas (2011), os quais fazem a crítica aos processos formativos centrados na "Epistemologia da Prática", assim como também recuperamos os elementos críticos acerca das atuais políticas de formação docente de Neves (2005, 2013 1, cuja ênfase reflexiva tem se desenvolvido a partir da tese que considera a atuação dos professores como intelectuais orgânicos da nova Pedagogia da Hegemonia. A partir do diálogo com as ideias expostas por esses autores, reunimos elementos que apresentam a hipótese da principal potencialidade que consideramos haver na política de formação de educadores do campo, qual seja, o potencial contra- hegemônico dessa política frente às atuais políticas de formação docente.

\section{A política hegemônica de formação de professores no Brasil frente às mudanças atuais no sistema produtivo}

Conforme explicitam autores como Frigotto (2010); Mancebo (201 0); Freitas (201 1); Neves (2005, 2013), a crise estrutural do capital tem rebatimentos diretos na educação. A necessidade de criação de nichos de acumulação, como também as mudanças requeridas no perfil dos trabalhadores - em função da intensa incorporação de novas tecnologias nos processos produtivos, visando à redução dos custos de produção das mercadorias -, faz com que a educação torne-se um dos grandes focos de interesse das classes dominantes no atual período histórico.

Como demanda do próprio capital, visando à recuperação e à manutenção das taxas de lucro, as intensas transformações foram se operando nas últimas décadas nos processos produtivos, as quais foram desenhando a superação do padrão taylorista/fordista de produção, para um padrão no qual se requer um trabalhador com habilidades bem maiores, que não podem ser apreendidas somente nas fábricas e que requerem um período mais longo de formação da classe trabalhadora. Para que ela possa desenvolver as 
habilidades requeridas a esses novos processos produtivos - que exigem sujeitos com maior capacidade de decisão, de compreensão, de flexibilidade, de adaptabilidade às transformações que continuamente se processam nas ithas de produção -, é imprescindível garantir a elevação dos níveis de escolaridade dos trabalhadores (FREITAS, 2011 ).

A necessidade das classes dominantes de ampliar o acesso à educação para as classes trabalhadoras, em função do novo perfil de trabalhador, capaz de se adequar e dar respostas às novas estratégias produtivas requeridas para manutenção das taxas de lucro do capital nessa fase de crise estrutural, incide direta e indiretamente nas disputas em torno das concepções que orientam as políticas de formação de educadores, dado o imenso peso que tem essa categoria na formação da visão de mundo dos jovens e crianças das novas gerações, de todos aqueles que passam pela escola (FREITAS, 2011 ; NEVES, 2005, 20131.

Além dos aspectos já descritos na teoria educacional acerca da relevância desse papel, mais um fator tem se somado a esse debate: a dimensão do número de profissionais atuando na educação no Brasil, transformando-os em uma das maiores categorias profissionais do País: 378 mil docentes na educação superior e 2 milhões de docentes na educação básica (NEVES, 20131.

A importância do papel desses profissionais, na formação da visão de mundo das novas gerações que passam pela escola, aliada ao tamanho dessa categoria, coloca, de acordo com Neves, as políticas de formação de educadores como parte relevante das disputas

[...] para construção e consolidação de qualquer projeto políitico-social na atualidade brasileira, quer seja pelo seu expressivo contingente, quer seja pela influência que exercem na conformação técnica e ético-política das novas gerações (NEVES, 2013, p. 2).

A citada autora indica que os professores têm um papel e uma função social extremamente relevante, porque possuem o potencial de atuar como intelectuais orgânicos, seja da hegemonia ou da contra-hegemonia. Baseada no pensamento gramsciano, que entende que todos os homens são intelectuais, exercendo, porém, em diferentes intensidades esse papel na sociedade em função das oportunidades de formação e dos locais que ocupam nesta mesma 
Política de formação de educadores do campo no contexto da expansão da educação superior

sociedade, Neves (2013) nos apresenta a hipótese de que, no momento atual, os professores, de maneira geral, estariam sendo preparados para atuar como intelectuais orgânicos da nova pedagogia da hegemonia, sendo submetidos a processos aligeirados de formação, incapazes de oportunizar tempo e espaço para uma formação omnilateral, sendo essa perspectiva substituída por uma formação fragmentada, excessivamente focada na prática, desprovida de uma adequada fundamentação teórica e, pior, apartada da necessária formação de valores que devem integrar a formação docente.

Essa lógica de formação docente acaba por encontrar o caminho da superação da contradição vivenciada pelos capitalistas de, ao mesmo tempo, ter que elevar os níveis de escolaridade dos trabalhadores, sem, porém, aumentar os níveis de consciência e compreensão deles, sobre os injustos processos de trabalho aos quais são submetidos, sob o modo de produção capitalista (FREITAS, 2011 ).

A referida formação docente, aligeirada, precarizada, sem a devida fundamentação teórica, dissociadora da teoria e da prática, realizada sem a presença e a participação do futuro educador na vida escolar, e também ainda sem a necessária garantia do acesso aos conteúdos específicos da área 126 de formação para o qual se titula esse docente, tem sido objeto de intensa pesquisa e reflexão na área de formação de educadores, expondo, de maneira flagrante, os imensos prejuízos à qualidade da educação no País.

$\bigcirc$ estudo realizado por Ferreira (2011) indica que, para compreender, na atualidade, a política hegemônica de formação de professores, faz-se necessária uma incursão pelas legislações educacionais brasileiras promulgadas a partir da década de 1990 no contexto das reformas educacionais em curso, e orientadas pela forte presença dos organismos internacionais.

Essas reformas se fundamentaram num modelo de administração pautado pela eficiência, eficácia, produtividade e gerência racional dos recursos humanos e sociais, e foram orientadas por organismos internacionais, como Banco Mundial; Fundo Monetário Internacional; Organização das Nações Unidas para a Educação, Ciência e Cultura; Organização de Cooperação e Desenvolvimento Econômico, entre outros, a partir da compreensão de que a promoção da escolarização mínima para a população estimularia o desenvolvimento do País, garantindo a entrada no mercado, de maneira mais 
competitiva e forte. A título de exemplo, o Banco Mundial em suas prescrições indica ser

[...] a educação um importante instrumento de promoção de crescimento econômico e da redução da pobreza. [...] A educação pode ajudar a reduzir a desigualdade, proporcionar novas oportunidades aos pobres e, conseqüentemente, aumentar a mobilidade social (BANCO MUNDIAL, 1995, p. 18).

Entre as legislações educacionais brasileiras, segundo Ferreira (201 1), que mais diretamente interferem na definição das políticas de formação inicial e continuada de professores e estabelecem os parâmetros para a definição do perfil e do trabalho docente encontram-se: o Plano Decenal de Educação de 1993 (BRASIL, 2003) - que destaca a importância e estabelece diretrizes para a formação docente; a Lei de Diretrizes e Bases da Educação Nacional (LDB - Lei n 9.394, de 20 de dezembro de 1996) - que dedica um capítulo específico a esse tema; os Parâmetros Curriculares Nacionais (PCN - 1997) - que inclui a formação docente como objeto de estudo privilegiado na formação continuada, nas escolas brasileiras; os Sistemas Nacionais de Avaliação - Sistema de Avaliação da Educação Básica (SAEB - BRASIL, 2005) e Exame Nacional de Ensino Médio (ENEM) - que impõem mudanças na condução da formação e trabalho docente no cotidiano escolar; o Plano Nacional de Educação (PNE - Lei n 10.172, de 9 de janeiro de 2001, Seção IV/Magistério da Educação Básica, subseção 10/Formação e valorização do magistério); o Plano de Desenvolvimento da Educação (PDE - 2007) - que aponta a formação docente como um dos principais instrumentos para a melhoria da qualidade da educação básica; o Plano de Metas Compromisso Todos pela Educação (Decreto n. 6.094, de 24 de abril de 2007 - BRASIL, 2007) - que estabelece como um dos pontos básicos a formação docente; a Política Nacional de Formação de Profissionais do Magistério da Educação Básica (Decreto n 6.755, de 29 de janeiro de 2009 - Portaria Normativa $n^{\circ}$ 9, de 30 de junho de 2009) - que institui o Plano Nacional de Formação dos Professores da Educação Básica no âmbito do Ministério da Educação; a criação da "Nova CAPES" (Lei n 11 .502, de 11 de julho de 2007 - BRASIL, 2007a) - que passa a ser a agência reguladora da formação docente da educação básica pela via do Departamento de Educação Básica. 
Política de formação de educadores do campo no contexto da expansão da educação superior

Essas legislações, no conjunto, determinam referências e parâmetros que direcionam as políticas e o trabalho docente em sua natureza e função, vinculando diretamente os professores e sua formação como responsáveis pelos graves problemas educacionais vivenciados no Brasil, e, ao mesmo tempo, estabelecendo, como solução para essa problemática, a promoção de mudanças substantivas na qualificação técnico-profissional dos docentes, bem como nos métodos e organização dos sistemas e das unidades escolares, em duas dimensões: reestruturação da formação inicial dos profissionais; e revisão, sistematização e expansão da formação continuada dos profissionais da educação básica.

A maioria das legislações mencionadas anunciam a importância da articulação entre teoria e prática na formação dos professores, entretanto, estabelecem que os processos formativos devem ser efetivados enquanto capacitação em serviço, ou seja, no exercício da profissão docente, para assegurar aos professores a qualificação mínima exigida pela LDB, e devem ainda considerar os saberes e experiências anteriores dos docentes.

A capacitação em serviço fortalece a ideia de praticidade, compreendida como formação de "executores" do ensino, desprestigiando a sólida 128 fundamentação teórica ao priorizar o ativismo nas atividades em sala de aula, o que tem sido destacado por Freitas (2002) quando chama a atenção para a ênfase que as reformas educativas vêm atribuindo ao que acontece na sala de aula, em detrimento do que acontece, globalmente, na escola, retornando à concepção tecnicista de "Educação com uma nova roupagem."

A utilização da educação a distância na formação inicial e continuada dos professores também se constitui como indicação muito presente nessas legislações, o que, em grande medida, também dificulta a concretização da articulação entre teoria e prática, desconsiderando as dificuldades que se enfrenta para a promoção dessa intencionalidade nos cursos presenciais, tornando-se, na modalidade a distância, essa articulação ainda muito mais problemática.

Freitas (2007), em suas análises a respeito da política de formação docente, em face do caráter prioritário dado à Educação à Distância (EAD), especialmente a partir do surgimento da Universidade Aberta do Brasil (UAB), também chama atenção para a secundarização do conhecimento teórico, a negação dos fundamentos epistemológicos, e a valorização da Epistemologia 
da Prática e da lógica das competências, que permeia os programas e cursos de EAD. Na visão da autora, essas iniciativas, massificadas por intermédio da $U A B$, cumprem as metas estatísticas e conformam os professores a uma concepção de caráter subordinado, meramente instrumental, em contraposição à concepção do educador de caráter sócio-histórico, dos professores como profissionais da educação, intelectuais essenciais para a construção de um projeto social emancipador que ofereça novas possibilidades à educação da infância e da juventude (FREITAS, 2007).

Na visão da Associação Nacional pela Formação dos Profissionais da Educação - Anfope (2002), os cursos de formação inicial e continuada de professores sob a modalidade da EAD são efetivados como uma política compensatória, que visa suprir a ausência de oferta de cursos permanentes dirigidos a segmentos populacionais historicamente afastados da rede pública de educação superior, como os professores leigos, levando o Ministério da Educação a propor ações articuladas com as secretarias de educação estaduais e municipais para promover a formação dos professores nessa modalidade.

Essas orientações reforçam a atividade docente como um ofício predominantemente técnico, induzindo os professores a se tornar "consumidores" de cursos de formação a fim de adquirirem competências para o ingresso e permanência no mercado de trabalho; situação essa que se coaduna com as afirmações de Mavés (2005), quando afirma que a adoção da pedagogia das competências na formação docente tem aproximado a escola da lógica do mercado, oferecendo uma formação que atende às exigências do mundo empresarial em detrimento de uma formação geral e crítica; e deve formar um professor "[...] capaz de seguir a flexibilização do mercado, que seja polivalente e que tenha a sua subjetividade trabalhada para incorporar essa nova fase do capitalismo como algo normal e inevitável" (MAUÉS, 2005, p. 94-95).

Nessa mesma perspectiva, a pesquisa tem sido destacada como elemento importante nos cursos de formação inicial e continuada de professores, entretanto, o foco tem sido predominantemente o processo de ensino e aprendizagem, no sentido de que os professores devem dispor de conhecimentos e mobilizá-los para a ação docente (BRASIL, 2002).

Todas essas estratégias terminam por convergir com a ênfase que tem sido dada à formação e valorização dos professores como determinante para melhoria da qualidade da educação, referendada pelas legislações 
Política de formação de educadores do campo no contexto da expansão da educação superior

educacionais vigentes e pelo discurso dos gestores públicos educacionais em todas as esferas de governo, quando estabelecem como foco da formação dos professores a aprendizagem dos alunos aferida por meio de resultados concretos a serem atingidos; quando vinculam a formação dos professores à alfabetização em tempos predeterminados, com acompanhamento dos alunos individualmente mediante registro de seu desempenho por meio de exames periódicos específicos; quando instituem programas de formação inicial e continuada de formação de professores em regime de colaboração articulados à implantação do plano de carreira, cargos e salários para os profissionais da educação, privilegiando a promoção por mérito e a avaliação de desempenho.

De fato, a partir da implementação do "Plano de Metas Compromisso Todos pela Educação", o Índice de Desenvolvimento da Educação Básica (ldeb) - idealizado a partir de experiências da Organização para Cooperação e o Desenvolvimento Econômico, com o Programa Internacional de Avaliação de Alunos (Pisa) (BRASIL, 2010) -, se tornou instrumento de regulação da política de formação docente na atualidade e indicador oficial de qualidade da educação pública brasileira.

Essa visão de qualidade tem sido apontada como limitada e reducionista pelo conjunto de entidades que atuam diretamente com a formação dos educadores em nível nacional: Associação Nacional de Pesquisa e PósGraduação em Educação (ANPEd), Centro de Estudos Educação \& Sociedade (Cedes), Associação Nacional de Política e Administração da Educação (Anpae), Associação Nacional pela Formação dos Profissionais da Educação (Anfope), Fórum Nacional de Diretores de Faculdades e Centros de Educação (Forumdir) e Confederação Nacional dos Trabalhadores em Educação (CNTE).

Essas instituições apontam que essa concepção de qualidade é extremamente perversa quando passa a ser utilizada como referência para a avaliação do desempenho dos próprios professores em seu trabalho docente, especialmente quando priorizam o desempenho satisfatório dos professores em exames nacionais; domínio de conhecimentos, habilidades e competências estabelecidas previamente; emprego de tecnologias avançadas com fim em si mesmas; supervalorização da competitividade e da produtividade; novos métodos de gerenciar sistemas e instituições educacionais sob a ótica empresarial; procedimentos integrados e flexíveis no trabalho pedagógico que restrinjam a 
atuação dos profissionais da educação (ANFOPE; ANPAE; ANPEd; CEDES; CNTE; FORUNDIR, 20111.

Estabelece-se, assim, de maneira bastante articulada, a relação entre formação, valorização, trabalho docente e autonomia no quadro em que se estabelecem as políticas educacionais e os mecanismos de regulação que passam a envolver o trabalho docente.

O estudo de Reis (2014) nos ajuda a compreender melhor a articulação referida ao afirmar que, com a implementação das políticas de formação de professores em curso, a autonomia está perdendo espaço para a responsabilização do trabalho docente, uma vez que os discursos da competência na formação e trabalho docente, por elas evidenciado, mascaram a face da autonomia visto que o controle exercido pelos programas de formação continuada, pelos modelos estandardizados de avaliação e os materiais pedagógicos utilizados como padrão de aplicabilidade para os alunos de maneira uniforme, deixa margem à afirmativa de que a autonomia, na fase atual do trabalho docente é, no mínimo, questionável.

Peroni (2010), em seus estudos, colabora com essa discussão acerca da autonomia dos professores quando destaca que uma das estratégias comumente utilizada para fortalecer o processo de regulação em curso do trabalho decente, com a utilização de ações intensivas de formação dos professores, são as parcerias entre a esfera pública e a privada, implementadas para a melhoria da qualidade do ensino. Sob a ótica da racionalidade técnica no intuito de atender às recomendações do Banco Mundial, Programas como "Gestão Nota 10" e "Escola Campeã" entre outros, implantados nas redes de ensino por meio de parcerias com o Instituto Ayrton Senna e o Grupo de Estudos sobre Educação, Metodologia de Pesquisa e Ação (Gempa), por exemplo, diminuem a autonomia dos docentes, mediante utilização de materiais didáticos que os professores recebem prontos, e com um supervisor que verifica a aplicação do material, envolvendo o desempenho cognitivo dos alunos e os fluxos de aprovação, reprovação e evasão, associado à premiação por desempenho.

Essas iniciativas todas, no conjunto, fortalecem o argumento de Contreras (2002) ao afirmar que a autonomia na atual conjuntura de modificações da docência tornou-se ambígua, pois se, de um lado, solicita dos trabalhadores docentes iniciativa e criatividade, de outro, cria estratégias de 
Política de formação de educadores do campo no contexto da expansão da educação superior

controle desse trabalho. Elas se afastam das demandas dos movimentos sociais populares do campo que se inserem no movimento contra-hegemônico de transformação das políticas públicas de educação no Brasil, a fim de romper com as limitações impostas pela formação profissional que visam responder às demandas atuais do sistema produtivo.

A perversidade da lógica de avaliação implementada, de acordo com Neves (2005, 2013) e Freitas (2012), está absolutamente interligada às maiores intencionalidades desse sistema: estimular a competição, o individualismo, o egoísmo. A estratégia de ranqueamento entre as escolas, a lógica de premiação de docentes, os bônus salariais, enfim, os vários elementos que integram a política que promovem a competição entre os próprios docentes de uma mesma escola, e pior, entre as escolas, desconstruindo, cada vez mais, a ideia de uma rede escolar e um sistema de ensino, produzem nefastas consequências. Além de desestimular o trabalho coletivo entre os docentes e abortar possibilidades de articulação entre as escolas, acaba por cultivar, nos professores, os valores competitivos, antissolidários, o que acaba levando-os à reprodução desses valores com os educandos que convivem. Por isso, Neves (2013) os colocam como intelectuais orgânicos da hegemonia: porque esta132 riam reproduzindo os valores da sociedade capitalista.

Uma das principais marcas da chamada "Epistemologia da Prática" refere-se exatamente à ideia de que a resolução dos graves problemas educacionais, enfrentados pelo sistema público de ensino do País, adviria do aumento da capacidade do próprio educador de refletir sobre sua própria prática docente e de promover transformações em seus processos de ensino e aprendizagem que, ao serem efetuadas por si só, resolveriam os problemas educacionais do Brasil, ignorando e desconsiderando todos os demais fatores externos e estruturais que integram os dilemas educacionais do País.

Ao contrário dessa concepção, a estratégia formativa que subjaz à política de formação de educadores do campo desenhada na matriz das Licenciaturas em Educação do Campo, concebida a partir da pressão dos movimentos sociais, revela uma concepção que não adere aos propósitos das políticas neoliberais, de responsabilização e individualização do docente sobre o êxito ou fracasso do aluno, sem considerar todas as condições socioeconômicas e culturais que envolvem os processos de aprendizagem (FREITAS, 1999; 2003). E, ao mesmo tempo, não desresponsabiliza o educador da condução dos processos didáticos, dando-lhe, porém, condições de compreender, 
criticamente, sua própria prática, qualificando-o, cada vez mais, à luz de maior compreensão e complexificação das teorias que têm orientado sua ação pedagógica.

Essa é exatamente a cilada da perspectiva neoliberal das políticas de formação, ao colocar somente sobre o docente a responsabilidade da transformação dos problemas educacionais, portanto, como destaca Silva, se a questão da relação teoria prática no processo de formação docente for colocada sobre esses parâmetros,

[...] haverá dificuldades de estabelecer unidade entre as duas atividades humanas: teórica e prática, pois em tais circunstâncias a unidade refere-se ao fazer, não questionando a direção, o sentido e a política da ação (SILVA, 2012 , p. 269).

Numa perspectiva contrária, as reivindicações dos movimentos sociais quanto às políticas e práticas de formação docente priorizam a formação humana dos educadores do campo, a fim de se colocar como agente participativo na construção de um novo projeto de desenvolvimento para o País, que afirme o lugar do campo nesse novo projeto. E, a partir de intensas lutas por direitos, que tem como elementos centrais o direito à terra e à educação, - Movimento da Educação do Campo conquista uma política específica de formação de educadores, porém sem descolar essa política do conjunto das tensões e contradições nas quais serão executados os processos de formação que ficarão sob a responsabilidade desses educadores.

A política de formação de educadores do campo compreende a necessidade de construir estratégias formativas que sejam capazes de oportunizar ao docente em formação a superação dessa visão restrita dos limites e potenciais de sua ação, ofertando-lhes, durante o percurso formativo, os fundamentos filosóficos, sociológicos, políticos, econômicos, antropológicos capazes de thes dar elementos para ir localizando os efeitos e resultados de sua ação educativa a partir de um contexto bem mais amplo que a contém, especialmente as tensões e contradições que permeiam as relações sociais no território rural contemporaneamente, com ênfase nos desafios impostos à permanência dos sujeitos camponeses nesse território a partir do avanço cada vez mais desenfreado do agronegócio, que promove uma fagocitose não só das escolas rurais, mas também das próprias comunidades que aí vivem (MOLINA, 2014). 
Com base nas próprias concepções originárias do Movimento da Educação do Campo, não há sentido formar um educador do campo que não seja capaz de compreender as contradições e os processos de acumulação de capital no campo. A formação proposta pela Licenciatura em Educação do Campo, que, em seu Projeto-Político Pedagógico, enfatiza exatamente os componentes curriculares que pouco aparecem ou são ausentes nos cursos tradicionais de formação de educadores, como: economia política, história, filosofia, sociologia, entre outros, que tem por intencionalidade oportunizar formação crítica dos educadores.

\section{Contextos de criação e expansão do Programa de Apoio às Licenciaturas em Educação do Campo}

Um dos diferenciais das políticas públicas de Educação Campo pautadas pelos movimentos sociais refere-se ao seu protagonismo, durante a primeira década da história desse Movimento, na concepção e elaboração das principais políticas educacionais para os camponeses: o Programa

134 Nacional de Educação na Reforma Agrária, o Programa Residência Agrária e - Programa Saberes da Terra, por exemplo.

Todavia, esse protagonismo tem sido ameaçado e se transformado em mera representação formal, sem uma efetiva participação na concepção e no modus operandi das políticas públicas, à medida que foram se intensificando as mudanças do modelo de desenvolvimento no campo, a partir da consolidação do agronegócio no País, e que a correlação de forças foi se transformando, a começar da configuração da nova aliança de classes em função dos novos interesses econômicos no campo e do aumento das estratégias de criminalização dos movimentos sociais na mesma época.

Conforme análise do próprio Fórum Nacional de Educação do Campo (FONEC), o período inicial do Movimento da Educação do Campo coincide com o período de transição que tem sido compreendido como da crise do latifúndio à consolidação do Agronegócio. Foi, aliás, esse período, de certa fragilidade da aliança das classes dominantes, que possibilitou o crescimento e avanço das lutas pelos direitos no campo.

$\bigcirc$ documento do referido Fórum reconhece que o crescimento da Educação do Campo, àquela época, foi possível em função de determinada 
correlação de forças existentes no período: é possível afirmar que ocupamos um "vácuo" de transição de modelos (ajustes no modelo macroeconômico brasileiro, capitalista, neoliberal)

[...] entre a crise do latifúndio e a emergência do agronegócio os movimentos sociais de luta pela terra e pela Reforma Agrária ganharam ímpeto, conquistamos o PRONERA e constituímos a Educação do Campo (FONEC, 2012, p. 4).

Como parte daquela conjuntura, o Procampo é uma política de formação de educadores, conquistada a partir da pressão e das demandas apresentadas ao Estado pelos movimentos sociais. Pautada desde a primeira Conferência Nacional por Uma Educação Básica do Campo (CNEC), realizada em 1998, a exigência de uma Política Pública específica para garantir a formação de educadores do campo vai se consolidar também como uma das prioridades requeridas ao término da II CNEC, realizada em 2004, cujo lema era exatamente "Por Um Sistema Público de Educação do Campo."

A partir da intensa cobrança dos movimentos sociais que seguiam pressionando para o atendimento das pautas da II CNEC, é instituído um Grupo de Trabalho que fica responsável pela elaboração da proposta que deveria subsidiar a Secretaria de Educação Continuada, Alfabetização, Diversidade e Inclusão - Secadi, na proposição ao MEC, de um plano de formação de educadores campo.

Os movimentos demandam e logram nesse período a conquista de um processo de elaboração bastante articulado com suas representações. Após os encontros específicos do Grupo de Trabalho, para imprimir forma ao primeiro desenho dessa política de formação, foram realizadas também com suas representações alguns encontros nos quais se submeteu ao debate a proposta elaborada, a fim de se chegar à versão a ser apresentada às instâncias do Ministério da Educação (MEC), responsáveis pela implementação do Programa, que aprovou o desenho das Licenciaturas em Educação do Campo (MOLINA, 2014).

A implantação dessa política se inicia por meio de uma experiência piloto, com a construção de quatro cursos que foram realizados com base em convites efetuados pelo MEC a partir de indicações de IES pelos movimentos sociais, ligadas à Educação do Campo (UFMG, UnB, UFBA e UFS). Com essas experiências piloto ainda em execução, a começar da imensa demanda 
Política de formação de educadores do campo no contexto da expansão da educação superior

de formação de educadores do campo e da pressão dos movimentos sociais, - MEC lança editais em 2008 e 2009 para que novas instituições pudessem ofertar a Licenciatura em Educação do Campo. Porém, sem nenhuma garantia de sua continuidade e permanência, uma vez que a oferta por meio desses Editais fez-se mediante aprovação de projetos especiais, tramitados e autorizados somente para uma turma.

Esse foi um dos pontos que teve intenso questionamento dos movimentos. A demanda para a formação de educadores do campo, além de ter que ser capaz de suprir o enorme passivo existente, deveria ser permanente para garantir o direito à educação aos sujeitos do campo, desde as suas especificidades.

A conquista pelos movimentos sociais, da assinatura do Decreto n. 7352, de 4 de novembro de 2010, o qual instituiu a Política Nacional de Educação do Campo, exigiu a elaboração do Pronacampo, e para dar materialidade às ações previstas no referido Decreto, institui-se, em 2012, outro Grupo de Trabalho, para conceber as ações que integrariam o citado Programa.

Embora aquém da demanda existente, o Pronacampo estabelece meta ambiciosa para três anos: a formação de 45 mil educadores do campo - quantitativo que deveria ser distribuído entre três estratégias de formação que ocorreriam simultaneamente, isto é, os próprios cursos do Procampo -, os cursos desenvolvidos por meio da Plataforma Freire via Parfor (CAPES, 2011 l, e a terceira via mais problemática, por meio da Educação a Distância, via UAB. Alvo de profundas e pertinentes críticas do Movimento da Educação do Campo, esta última estratégia não foi ainda iniciada, não sendo, porém, o caso da oferta da formação de educadores do campo via Parfor, cujo crescimento tem sido expressivo. Já existem pesquisas (BRITO, 2013) que analisam a inadequação desses cursos aos educadores do campo, não sendo incorporadas, em seu currículo, as especificidades da formação dos educadores do campo (MOLINA, 2014). 


\section{Especificidades que configuram a Licenciatura em Educação do Campo}

Os cursos de Licenciatura em Educação do Campo têm por objeto a escola de Educação Básica, com ênfase na construção da Organização Escolar e do Trabalho Pedagógico para os anos finais do ensino fundamental e do ensino médio. Esses cursos objetivam preparar educadores para, além da docência, atuar na gestão de processos educativos escolares e na gestão de processos educativos comunitários.

A organização curricular dessa graduação prevê etapas presenciais (equivalentes a semestres de cursos regulares), ofertadas em regime de alternância entre Tempo Escola e Tempo Comunidade, tendo em vista a articulação intrínseca entre educação e a realidade específica das populações do campo. Essa metodologia de oferta intenciona também evitar que o ingresso de jovens e adultos na educação superior reforce a alternativa de deixar de viver no campo, bem como objetiva facilitar o acesso e a permanência no curso dos professores em exercício nas escolas do campo (MOLINA; SÁ, 2011 ).

A matriz curricular proposta desenvolve uma estratégia multidisciplinar de trabalho docente, organizando os componentes curriculares a partir de quatro áreas do conhecimento: Artes, Literatura e Linguagens; Ciências Humanas e Sociais; Ciências da Natureza e Matemática; e Ciências Agrárias.

A habilitação de docentes por área de conhecimento tem como um dos seus objetivos ampliar as possibilidades de oferta da educação básica no campo, especialmente no que diz respeito ao ensino médio, mas a intencionalidade maior é a de contribuir com a construção de processos capazes de desencadear mudanças na lógica de utilização e de produção de conhecimento no campo, desenvolvendo processos formativos que contribuam com a maior compreensão dos sujeitos do campo da totalidade dos processos sociais nos quais estão inseridos (MOLINA; SÁ, 20111 ).

Ao construir como perfil de habilitação da Licenciatura em Educação do Campo simultaneamente as três dimensões /docência por área de conhecimento; gestão de processos educativos escolares; e gestão de processos educativos comunitários), idealizou-se a perspectiva de promover e cultivar determinado processo formativo que oportunize aos futuros educadores, ao mesmo tempo, formação teórica sólida, que proporcionasse o domínio dos 
Política de formação de educadores do campo no contexto da expansão da educação superior

conteúdos da área de habilitação para o qual se titula o docente em questão, extremamente articulada ao domínio dos conhecimentos sobre as lógicas do funcionamento e da função social da escola e das relações que esta estabelece com a comunidade do seu entorno (MOLINA, 2014).

A formação por áreas de conhecimento deve desenvolver-se tendo como intencionalidade promover estratégias que contribuam para superar a fragmentação do conhecimento, criando e promovendo ações docentes articuladas interdisciplinarmente, associadas intrinsecamente às transformações no funcionamento da escola e articuladas, ainda, às demandas da comunidade rural na qual se insere a escola. A proposta e o desafio é realmente materializar práticas formativas durante o percurso da Licenciatura em Educação do Campo que sejam capazes de ir desenvolvendo e promovendo nos futuros educadores as habilidades necessárias para contribuir com a consolidação do ideal de escola edificado por esse movimento educacional protagonizado pelos movimentos sociais nos últimos 15 anos: uma Escola do Campo (MOLINA; SÁ, 2012).

Apostando na compreensão gramsciana da escola como importante lócus de produção de contra-hegemonia aos valores da sociedade capitalista, 138 o Movimento da Educação do Campo trabalha com a perspectiva de formar educadores camponeses que possam atuar nessas escolas como intelectuais orgânicos da classe trabalhadora (GRAMSCl, 1991) contribuindo, por sua vez, com a formação crítica dos educandos que passem por essas unidades escolares, dando-thes condições de compreender os modelos de desenvolvimento do campo em disputa, como parte integrante da totalidade de projetos societários distintos, entre a classe trabalhadora e a capitalista (MOLINA, 2014).

$\bigcirc$ pano de fundo desse debate, tão central à compreensão e reflexão a respeito das políticas de formação de educadores, diz respeito ao tipo de trabalho desenvolvido por esses profissionais: se teria ele um caráter material ou imaterial. Os professores, ao trabalharem com seus educandos, agem sobre o pensamento e sobre a visão de mundo desses sujeitos. E possui um papel de extrema relevância na conformação do tipo de ação que eles podem vir a desenvolver, ressalvando-se, necessariamente, o espaço de autonomia de cada indivíduo na eleição da leitura de mundo que orientará sua ação. Em relação a esse debate, Trojan afirma que 
[...] a essência da atividade docente profissional, ou seja, o processo de ensino e aprendizagem envolve conhecimentos teóricos e práticos porque é uma atividade intencional que exige conhecimentos, estabelecimento de objetivos, planejamento, intervenção e avaliação para atingir sua finalidade. Por essa razão, deve ser cientifica e sistemática e não espontânea e casual, pois envolve um processo de transformação da realidade, cujo resultado deve ser a aprendizagem dos elementos necessários para a formação humana em determinado contexto social. Esta atividade cognitiva e teleológica, enquanto atividade da consciência é teórica, não se materializa, mas é fundamental para guiar a ação propriamente dita [...] Na atividade prática realiza-se o projeto idealizado teoricamente. Na atividade prática 'o sujeito age sobre uma matéria que existe independente de sua consciência', cujo processo e resultado não é uma mera aplicação da teoria, mas um conjunto de ações que implicam em vencer a resistência do objeto, que implica em interação, que exige realimentação para superar imprevistos. Isso significa que a relação teoria-prática é um processo indissociável e incessante, no entanto, não dissolve uma dimensão na outra (TROJAN, 2008, p. 37).

Assim, a matriz formativa proposta pelas Licenciaturas em Educação do Campo revela que a sua concepção formativa não acata o engodo das políticas neoliberais, de responsabilização e individualização do docente sobre o êxito ou fracasso do aluno, tal como propõe a Epistemologia da Prática, sem considerar todas as condições socioeconômicas e culturais que envolvem os processos de aprendizagem (FREITAS, 1999, 2003). E, ao mesmo tempo, não desresponsabiliza o educador da condução dos processos didáticos, dando- the, porém, condições de compreender, criticamente, sua própria prática, qualificando-o, cada vez mais, à luz de maior compreensão e complexificação das teorias que têm orientado sua ação pedagógica.

A diferença de concepção e estratégia do processo formativo proposto pela LEDOC, no tocante a esse ponto tão nevrálgico da formação de educadores, reside no fato de que sua concepção de prática não se restringe a uma "[...] perspectiva pragmática, em que o critério de verdade e associação da teoria/prática é o êxito, a eficácia da ação, entendida como prática individual" (SILVA, 2012 , p. 278).

A política de formação docente proposta pela Educação do Campo, ao que se pode constatar na matriz formativa construída pelos movimentos 
Política de formação de educadores do campo no contexto da expansão da educação superior

sociais que estiveram presentes na elaboração do desenho do Procampo, tem profunda compreensão da necessidade de construir estratégias formativas que sejam capazes de oportunizar ao docente em formação a superação da visão restrita dos limites e potenciais de sua ação, ofertando-lhes, durante o percurso formativo, os fundamentos teóricos necessários para o educador ir localizando os efeitos e resultados de sua ação educativa a partir de um contexto bem mais amplo que a contém.

Com a intencionalidade de formar educadores capazes de compreender a totalidade dos processos sociais em que estão inseridos os educandos do campo - com os quais docentes em formação irão trabalhar -, a referida Licenciatura tem buscado promover práticas educativas que sejam capazes de criar condições necessárias para a compreensão dos processos sociais de ensino-aprendizagem nessa dimensão. $\bigcirc$ que tem requerido que, nessa graduação, se façam presentes componentes curriculares que trabalhem com os conteúdos da Economia Política, da História, da Sociologia, da Filosofia, da Antropologia, entre outros tantos que, articuladamente, a partir de um intenso trabalho interdisciplinar, vão contribuindo para ampliar e alargar a visão de mundo desses educadores em formação (MOLINA, 2014).

Portanto, a compreensão da totalidade dos processos envolvidos na relação ensino-aprendizagem se dá desde a construção de uma leitura integral dos processos sociais, econômicos, políticos, culturais envolvidos na relação educador-educando para um posterior refazimento do peso de cada um desses elementos nos resultados dos educandos, compreendidos, porém, como parte de uma totalidade com determinações exteriores a ela e ao que acontece em cada sala de aula, não sendo este o espaço único e central de resolução de todos os problemas dos processos de ensino-aprendizagem.

Essa relação é conflituosa para os educandos e para os professores universitários, porque exige que a matriz curricular dos cursos seja reorganizada em função das contradições que esses educandos trazem para os períodos de Tempo Escola, principalmente pela sua forte inserção na luta pela terra e pelos grandes tensionamentos pelos quais passa a Escola do Campo atualmente. Exige-se, nesses processos formativos, que não se descole a formação docente das lutas e proposições para melhorar a qualidade dos cursos de acordo com as exigências da Reforma Agrária e dos seus sujeitos. 
Dessa forma, trata-se de colocar a realidade como centro em torno do qual as ciências e outras formas de conhecimento se articulam, para que a realidade possa ser não apenas compreendida e analisada, mas também transformada. Há exigências concretas de um trabalho pedagógico que se centra no princípio da práxis, como modo de conhecimento que articula, em um mesmo movimento, teoria e prática, conhecimento e realidade. Assim, o trabalho pedagógico deve contribuir com a perspectiva de que os educandos desenvolvam a capacidade de articular a leitura de suas realidades, valendo-se do conhecimento científico, aprofundando desde as releituras e análises que vão se tornando complexas à medida que os educandos vão avançando em sua escolarização, no decorrer da alternância dos tempos e espaços educativos, qualificando, assim, as intervenções em suas comunidades.

Muito além de compreensões restritivas, essa experiência tem buscado orientar a formação dos educadores do campo, transitando entre aparência e essência e promovendo uma formação integral que thes possibilita internalizar os instrumentos, métodos, técnicas e teorias para conhecer, ler, interpretar e intervir na realidade onde atuam/atuarão, considerando as várias dimensões que a compõem: a própria sala de aula, a comunidade escolar, a inserção da escola num território do campo, as contradições e disputas presentes neste território, a inserção desse território nas contradições regionais e nacionais das lógicas de acumulação de capital no campo.

Portanto, a matriz formativa desenvolvida pela Licenciatura em Educação do Campo apresenta a intencionalidade pedagógica de formar um educador capaz de compreender a totalidade dos processos sociais nos quais se inserem sua ação educativa. Nessa matriz, a Alternância é compreendida tanto como metodologia, quanto também como pedagogia, materializando e oportunizando novas estratégias de produção de conhecimento que buscam verdadeiramente incorporar os saberes dos sujeitos camponeses. Em resumo, a contra-hegemonia na formação docente revela-se na articulação entre aparência e essência, a partir da qual se busca desenvolver uma formação em nível superior com qualidade social, com capacidade de formação de sujeitos camponeses educadores, com criticidade suficiente que thes permita olhar para a realidade na qual estão inseridos, o que inclui uma compreensão concreta das determinações que fazem com que essa realidade apareça tal qual ela está constituída, dando, porém, um passo além disso, sendo capazes de construir estratégias para intervir e transformar essa realidade. Para tanto, a Alternância 
apresenta-se como ferramenta fundamental, pois possibilita aproximar a universidade dos processos de produção de conhecimento e das contradições reais nas quais os sujeitos do campo estão inseridos durante o processo contínuo de materialização e construção da vida deles.

\section{Referências}

ANFOPE; ANAPE; ANPEd; CEDES; CNTE; FORUNDIR. Prova nacional de concurso para o ingresso na carreira docente: educação infantil e anos iniciais do ensino fundamental. 2011 . Disponivel em: http://anfope.spaceblog.com.br/1445203/Prova_Nacional-deConcurso-para-o-Ingresso-na-Carreira-Docente/. Acesso em: 29 jul. 2014.

ASSOCIAÇÃO Nacional de Pós-Graduação e Pesquisa em Educação. Documento Final. In: REUNIÃO ANUAL DA ASSOCIAÇÃO NACIONAL DE PÓS-GRADUAÇÃO E PESQUISA EM EDUCAÇÃO, 11 ., 2002, Florianópolis. Anais... Florianópolis: ANPEd, 2002.

BANCO MUNDIAL. Prioridades y estratégias para la educación. Washington, DC: Word Bank, 1995. Disponível em: hitp://www-wds.worldbank.org/external/default/ WDSContentServer/WDSP/IB/2005/06/13/000160016_20050613172136/ Rendered/PDF/14948010spanish.pdf. Acesso em: 15 ago. 2014.

BRASIL. Lei n ${ }^{\circ}$ 9.394, de 20 de dezembro de 1996. Estabelece as Diretrizes e Bases da Educação Nacional. Diário Oficial [da] República Federativa do Brasil, Poder Executivo, Brasília, DF, 23 dez. 1996, Seção 1, p. 27.833.

Secretaria de Educação Fundamental. Parâmetros curriculares nacionais: introdução aos parâmetros curriculares nacionais/Secretaria de Educação Fundamental. Brasília: MEC/SEF, 1997. 126p.

Presidência da república. Lei $\mathbf{n}^{\circ}$ 10.172, de 9 de janeiro de 2001. Aprova $\circ$ Plano Nacional de Educação para decênio 2001-2010, e dá outras providencias. 2001. Disponível em: hitp://www.planalto.gov.br/ccivil_03/leis/leis_2001/110172.htm. Acesso em: 10 dez. 2014.

Decreto $\mathbf{n}^{\circ}$ 6.094, de 24 de abril de 2007. Dispõe sobre a implementação do Plano de Metas Compromisso Todos pela Educação, pela União Federal, em regime de colaboração com Municípios, Distrito Federal e Estados, e a participação das famílias e da comunidade, mediante programas e ações de assistência técnica e financeira, visando a mobilização social pela melhoria da qualidade da educação básica. Disponível em: <http://www.planalto.gov.br/ccivil_03/_Ato2007-2010/2007/Decreto/D6094.htm>. Acesso em: 21 jun. 2014. 
Lei $n^{\circ}$ 11.502, de 11 de julho de 2007. Modifica as competências e a estrutura organizacional da fundação Coordenação de Aperfeiçoamento de Pessoal de Nível Superior - CAPES, de que trata a Lei $n^{\circ} 8.405$, de 9 de janeiro de 1992; e altera as Lei $n^{\circ}$ 8.405, de 9 de janeiro de 1992, e Lei n 11 1.273, de 6 de fevereiro de 2006, que autoriza a concessão de bolsa de estudo e de pesquisa a participantes de programas de formação inicial e continuada de professores para a educação básica. Disponível em: http://www. planalto.gov.br/ccivil_03/_Ato2007-2010/2007/Lei/L1 1502.htm. Acesso em: 21 jun. 2014.

Ministério da Educação. Plano Decenal de Educação para Todos. Brasília: MEC, 2003. (Versão acrescida, 136 p).

Portaria n 931, de 21 de março de 2005. Institui o Sistema de Avaliação da Educação Básica - SAEB. Diário Oficial [da] República Federativa do Brasil, Poder Executivo, Brasília, DF, 22 mar. 2005, Art. 1². p. 1.

. Resolução CNE/CP n 1, de 18 de fevereiro de 2002. Institui Diretrizes Curriculares Nacionais para a Formação de Professores de Educação Básica, em nível superior, curso de licenciatura, de graduação plena. Diário Oficial [da] República Federativa do Brasil, Poder Executivo, Brasília, DF, 4 mar. 2002, Art. 2 , p. 1. Brasília: INEP, 2010. Disponível em: http://www.inep.gov.br/internacional/pisa/. Acesso em: 26 jan. 2010.

Presidência da República. Decreto $\mathbf{n}^{\circ} \mathbf{7 . 3 5 2}$, de 4 de novembro de 2010. Dispõe sobre a política de educação do campo e o Programa Nacional de Educação na Reforma Agrária - PRONERA. Disponível em: http://www.planalto.gov.br/ccivil_03/_ ato20072010/2010/decreto/d7352.htm> Acesso em: 21 jun. 2014.

Decreto $n^{\circ}$ 6.755, de 29 de janeiro de 2009. Institui a Política Nacional de Formação de Profissionais do Magistério da Educação Básica, disciplina a atuação da Coordenação de Aperfeiçoamento de Pessoal de Nível Superior - CAPES no fomento a programas de formação inicial e continuada, e dá outras providências. Disponível em: http:// www. planalto.gov.br/ccivil_03/_ato2007-2010/2009/decreto/d6755.htm. Acesso em: 10 dez. 2014.

Ministério da Educação. Portaria Normativa nº 9, de 30 de junho de 2009.

Institui o Plano Nacional de Formação dos Professores da Educação Básica no âmbito do Ministério da Educação. 2009. Disponível em: http://www.abdir.com.br/legislacao/legislacao_abdir_1_7_09_4.pdf. Acesso em: 10 dez. 2014. 
Política de formação de educadores do campo no contexto da expansão da educação superior

Coordenação de Aperfeiçoamento de Pessoal de Nível Superior. Plano Nacional de Formação de Professores da Educação Básica - PARFOR. Brasília, 2011. Disponível em: <http://www.capes.gov.br/educacao-basica/parfor>. Acesso em: 12 ago. 2014.

BRITO, Márcia Mariana Bittencourt. $O$ acesso à educação superior pelas populações do campo, na universidade pública: um estudo do PRONERA, PROCAMPO e PARFOR, na Universidade Federal do Pará. 2013. 131f. Dissertação (Mestrado em Educação) Programa de Pós-Graduação em Educação, Universidade Federal do Pará, Belém, 2013.

CONTRERAS, José. A autonomia de professores. Tradução Sandra Trabucco Valenzuela. São Paulo: Cortez, 2002.

FERREIRA, Diana Lemes. A Organização para Cooperação e Desenvolvimento Econômico (OCDE) e a Política de Formação Docente no BRASIL. 201 1. 330f. Tese (Doutorado em Educação) - Programa de Pós-Graduação em Educação, Universidade Federal do Pará, Belém, 2011.

FREITAS, Helena Costa. A reforma do ensino superior no campo da formação dos profissionais da educação básica: as políticas educacionais e o movimento dos educadores. Educação \& Sociedade, Campinas, v. 20, n. 68, p. 17-43, dez. 1999

Formação de professores no Brasil: 10 anos de embate entre projetos de formação. Educação \& Sociedade, Campinas, v. 23, n. 80, p. 137-168, set. 2002.

Certificação docente e formação do educador: regulação e desprofissionalização. Educação \& Sociedade, Campinas, v. 24, n. 85, p. 1095-1 124, 2003.

A (nova) política de formação de professores: a prioridade postergada. Educação \& Sociedade, Campinas, v. 28, n. 100, p. 1203-1230, out. 2007. (Número Especial).

FREITAS, Luiz Carlos de. Neotecnicismo e formação do educador. In: ALVES, Nilda (Org.) Formação de professores: pensar e fazer. São Paulo: Cortez. 2011.

Os reformadores empresariais da educação: da desmoralização do magistério à destruição do sistema público de educação. Educação \& Sociedade, Campinas, v. 33, n. 119 , p. 379-404, jun. 2012.

FRIGOTTO, Gaudêncio. Educação e a crise do capitalismo real. 6. ed. São Paulo: Cortez, 2010.

FONEC. Notas para análise do momento atual da educação do campo. In: SEMINÁRIO NACIONAL, 2012, Brasília. Anais... Brasília, 2012. (digitalizado). 
GRAMSCl, Antonio. Os intelectuais e a organização da cultura. Rio de Janeiro: Civilização Brasileira, 1991.

MANCEBO, Deise. Reforma da educação superior: o debate sobre a igualdade de acesso. In: BITTAR, Mariluce; OLIVEIRA, João Ferreira; MOROSINI, Marilia (Org.). Educação superior no Brasil - 10 anos pós-LDB. Brasília: Inep, 2010. p. 55-70.

MAUÉS, Olgaíses Cabral. $\bigcirc$ modelo de competências nas Diretrizes Curriculares da formação de professores. In: MAUÉS, Olgaíses Cabral; LIMA, Ronaldo (Org.). A lógica das competências na formação docente. Belém: EDUFPA, 2005. p. 93-112.

MOLINA, Mônica Castagna. Análises de práticas contra-hegemônicas na formação de educadores: reflexões a partir do Curso de Licenciatura em Educação do Campo. In: SOUZA, José Vieira (Org.) O método dialético na pesquisa em educação. Campinas: Autores Associados, 2014.

MOlINA, Mônica Castagna; SÁ, Laís Mourão. A licenciatura em educação do campo da Universidade de Brasília: estratégias político-pedagógicas na formação de educadores do campo. In: MOLINA, Mônica Castagna; SÁ, Laís Mourão (Org.) Licenciaturas em educação do campo - registros e reflexões a partir das experiências piloto. Belo Horizonte: Autêntica, 2011 .

Escola do campo. In: CALDART, Roseli Salete; PEREIRA, Isabel Brasil; ALENTEJANO,

Paulo; FRIGOTTO, Gaudêncio (Org.). Dicionário da educação do campo. São Paulo: Expressão Popular; Rio de Janeiro: Escola Politécnica de Saúde Joaquim Venâncio, 2012. p. 259-267.

NEVES, Lucia Wanderley (Org.). A nova pedagogia da hegemonia. Estratégias do capital para educar o consenso. São Paulo: Xamã, 2005.

professor como intelectual estratégico na disseminação da nova pedagogia da hegemonia. In: REUNIÃO ANUAL DA ASSOCIAÇÃO NACIONAL DE PÓS-GRADUAÇÃO E PESQUISA EM EDUCAÇÃO, 36., 2013, Goiânia. Anais... Goiânia: ANPEd, 2013.1 CD-ROM.

PERONI, Vera Maria Vidal. A parceria entre sistemas públicos de educação e o Instituto Ayrton Senna: implicações para o trabalho docente. In: SEMINÁRIO INTERNACIONAL DE FORMAÇÃO DE PROFESSORES PARA O MERCOSUL/CONE SUL, 18., 2010, Florianópolis. Anais... Florianópolis: UFSC, 2010. Disponível em: http://seminarioformprof. ufsc.br/files/2010/12/ PERONI-Vera-Maria-Vidal2.pdf. Acesso em: 15 ago. 2014. 
Política de formação de educadores do campo no contexto da expansão da educação superior

REIS, Maria Izabel Alves dos. $\mathbf{O}$ adoecimento dos trabalhadores docentes na rede púlica de ensino de Belém-Pará. 2014. 21 2f. Tese (Doutorado em Educação) - Programa de PósGraduação em Educação, Universidade Federal do Pará, Belém, 2014.

SIIVA, Kátia Agustas Curado Pinheiro Cordeiro da. Políticas públicas na formação de professores e a relação teoria e prática: um debate com Gramsci. In: CUNHA, Célio da; SOUSA, José Vieira de; SILVA, Maria Abádia da (Org.). Avaliação de políticas públicas de educação. Brasília: Liber Livro, 2012.

TROJAN, Rose Meri. Teoria e prática na formação docente: estudo das políticas educacionais brasileiras e cubanas. Práxis Educativa, Ponta Grossa, v. 3, n. 1, p. 29-42, jan./jun. 2008 .

Profa. Dra. Mônica Castagna Molina Universidade de Brasília | UnB

Centro Transdisciplinar de Educação do Campo e Desenvolvimento Rural Coordenadora da Pesquisa "Educação do Campo e Educação Superior: uma análise de práticas contra-hegemônicas na formação de profissionais da Educação e das Ciências Agrárias nas regiões Centro-Oeste, Nordeste e Norte" Pesquisadora da Rede Universitas/Br, na qual participa do Observatório da Educação "Políticas de Expansão da Educação Superior no Brasil"

E-mail | mcastagnamolina@gmail.com

\author{
Prof. Dr. Salomão Mufarrej Hage \\ Universidade Federal do Pará \\ Instituto de Ciências da Educação
}

Pesquisador da Rede Universitas/Br, na qual participa do Observatório da Educação "Políticas de Expansão da Educação Superior no Brasil" E-mail | salomao_hage@yahoo.com.br

Recebido 11 set. 2104 Aceito 19 fev. 2015 